\title{
Pediatric palliative care in Canada in 2012: a cross-sectional descriptive study
}

\author{
Kimberley Widger RN PhD, Dawn Davies MD MA, Adam Rapoport MD MHSc, \\ Christina Vadeboncoeur MD, Stephen Liben MD, Amrita Sarpal MD, Simone Stenekes RN MN, \\ Claude Cyr MD MSc, Lysanne Daoust RN MN, Marie-Claude Grégoire MD MSc, \\ Marli Robertson MBChB, Heather Hodgson-Viden MD, Julie Laflamme MD, Harold Siden MD MHSc
}

Abstract

Background: Pediatric palliative care focuses on comprehensive symptom management and enhancing quality of life for children with life-threatening conditions and their families. Our aim was to describe Canadian programs that provided specialized pediatric palliative care in 2012 and the children who received it and to estimate the proportion of children who might benefit that received specialized care.

Methods: A cross-sectional descriptive design was used. Specialized pediatric palliative care programs were included in the study if they offered multidisciplinary consulting pediatric palliative care services to a wide range of children and served all populations of children with life-threatening illness regardless of diagnosis. Investigators in programs that had taken part in a prior study were invited to participate. New programs that met the inclusion criteria were identified through snowball sampling within pediatric palliative care networks. Program data were obtained via surveys with coinvestigators, and health record reviews were used to obtain information about the children who received care through the programs.

Results: All 13 programs identified, including 3 with a free-standing hospice, agreed to take part in the study. Of the 1401 children who received care, $508(36.2 \%)$ were under 1 year of age, and $504(36.0 \%)$ had a congenital illness or condition originating in the perinatal period. Of the 431 children who died in 2012, 105 (24.4\%) died in a critical care setting. Programs with a hospice provided care to 517 children (36.9\%). Children in this group tended to be older, more often had a neurologic illness and received care for a longer time than those who received care from programs without a hospice. Overall, $18.6 \%$ (95\% confidence interval $17.1 \%-20.3 \%)$ of deceased children who might have benefitted from specialized pediatric palliative care based on diagnosis received such care, with 110 (25.2\%) receiving care for less than 8 days.

Interpretation: Program growth and changes in patients' demographic and clinical characteristics indicate improved reach of programs. However, barriers remain that prevent most children with life-threatening conditions from receiving specialized pediatric palliative care services.

$\mathrm{P}$ ediatric palliative care is an "active and total approach to care provided to children with life-threatening conditions and their families from the time of recognition or diagnosis of disease, throughout the illness, at the time of death and beyond. Pediatric palliative care includes management of symptoms, provision of respite, coordination of services, delivery of end-of-life care and provision of bereavement support." Although the principles of pediatric palliative care can and should be incorporated into care provided by any health care professional, there is increasing evidence suggesting that specialized programs may improve the quality of care for children and their families..$^{2-6}$

In 2002, there were 8 pediatric palliative care programs in Canada, 7 based in pediatric tertiary hospitals and 1 free- standing children's hospice. Clinicians from these programs conducted a study to describe program structures and populations served, and estimated that $5 \%$ of children who might benefit from specialized pediatric palliative care received care through one of the available programs. ${ }^{7}$ Since the study was carried out, there has been steady growth in the availability of

Competing interests: None declared.

This article has been peer reviewed.

Correspondence to: Kimberley Widger, kim.widger@utoronto.ca CMAJ Open 2016. DOI:10.9778/cmajo.20160054 
programs providing specialized pediatric palliative care to children with life-threatening conditions and their families. ${ }^{8}$ Given the growth in the number of programs and wider availability of hospices, it is important to systematically document the current service structure, the population receiving care and the proportion of children who now receive care through these programs in order to plan programs and resources needed to provide high-quality care for these children.

We performed a study to describe the provision of pediatric palliative care in Canada in 2012. Specific research questions included: 1) What are the structures, processes and outcomes of care provided by specialist pediatric palliative care programs in Canada in 2012? 2) Are there significant differences in children's demographic and clinical characteristics (e.g., age, diagnosis), processes of care (e.g., time from referral to death, time from "do not resuscitate" order to death) or outcomes of care (e.g., location of death) when pediatric palliative care is provided through a hospice versus a hospital-based program? 3) What proportion of children who might benefit received care through a specialized pediatric palliative care program?

\section{Methods}

We conducted a multicentre cross-sectional study, collecting data from multiple sources to compile a description of services and the population receiving them.

\section{Sample}

Specialized pediatric palliative care programs were included in the study based on criteria used in 2002: offered multidisciplinary consulting pediatric palliative care services to a wide range of children and served all populations of children with life-threatening illness regardless of diagnosis. The programs were composed of professionals with expertise in both pediatrics and palliative care and were recognized regionally as being specialized pediatric palliative care programs with designated resources to provide this specific care. ${ }^{7}$ The principal investigator (K.W.) contacted investigators in programs that had taken part in the 2002 study and invited them to participate. New programs that met the inclusion criteria were identified through snowball sampling within the Canadian Network of Palliative Care for Children and the Canadian Network of Pediatric Hospices; the resultant list was doublechecked against the list of tertiary children's hospitals in Canada to ensure no programs were missed. All programs identified agreed to take part in the study. In cases in which the same core staff provided care at a free-standing hospice and in the associated hospital, this was counted as 1 program.

\section{Setting}

A generalist level ${ }^{9}$ of pediatric palliative care can be and is provided by health care professionals across Canada. However, for this study we were interested in the care provided through programs with pediatric palliative care specialists that fit our inclusion criteria, as these types of programs are linked to higher-quality care. ${ }^{2-6}$ An important component of the setting of care in Canada is the availability of free-standing pediatric hospices, often associated with a children's hospital, that have been developed after the model of hospices in the United Kingdom. In contrast to "hospice care" in the United States, a term typically denoting additional resources provided at the end of life, often in the home, Canadian pediatric hospices refer to physical buildings that provide respite care earlier in the patient's course along with specialized palliative care services throughout the patient's course.

\section{Data collection}

Data were collected for all patients who received care through participating programs in 2012 (initial referral made during or before 2012 and child died in 2012 or was still alive and was being followed by the team at the end of 2012). The study data set was based on data collected in 2002 with an additional variable to indicate antenatal referrals, as this was raised as an emerging issue during the 2002 study (Appendix 1, available at www.cmajopen.ca/content/4/4/E562/suppl/DC1). Eligible patients were identified by the lead investigator at each site using clinical databases specific to the local program that included lists of all patients who had received care through the program. Any required data not available in the databases were collected through retrospective chart review conducted by the local investigator or a research assistant who received training from the principal investigator to ensure consistency across sites. All data were entered into the Research Electronic Data Capture database $;^{10}$ limits were set within the database to ensure that only data for eligible patients were entered.

We collected data about program structure and services via an email survey completed by the lead investigator at each program.

To estimate the proportion of children receiving specialized pediatric palliative care, we accessed vital statistics data from Statistics Canada on the population of children aged 19 years or younger and the total number and causes of childhood deaths in Canada during 2012. ${ }^{11}$

\section{Statistical analysis}

We summarized the data descriptively using frequencies and proportions. We compared hospice and nonhospice programs using the $\chi^{2}$ test (or Fisher exact test when the expected cell sizes were small). A $p$ value of less than 0.05 was used to determine statistical significance. We used SPSS version 22 to conduct the analyses. Missing data were few and were included as an "unknown" category for each variable.

\section{Ethics approval}

Research ethics board approval was obtained at each site before data collection.

\section{Results}

\section{Pediatric palliative care programs}

Thirteen programs met our inclusion criteria. Ten were based solely at tertiary hospitals, and 3 included a free-standing pediatric hospice. Table 1 lists the programs along with the start date, number of children who received care during 2012 and staffing. All programs functioned primarily in a consultative capacity but offered more front-line care at the end of life, particularly for managing challenging symptoms. Front-line care 


\section{OPEN}

Research

was provided to children admitted to 1 of the 24 beds available across all hospices for respite, pain and symptom management or end-of-life care. An additional 11 beds were designated for end-of-life care in the hospitals, and 2 programs had pediatric palliative care outpatient clinics. Most core teams consisted of a physician and a nurse, with some bereavement coordinators, psychologists or social workers, for a total of 39.61 full-timeequivalent staff designated for provision of specialist pediatric palliative care in 2012 (Table 1).

\section{Pediatric palliative care patients}

A total of 1401 children received specialized pediatric palliative care services in Canada in 2012 (Table 2). Included among the 1401 were 71 antenatal referrals $(5.1 \%)$ for a fetus with severe anomalies. Of the 1401 children, 431 (30.8\%) died during 2012, of whom $221(51.3 \%)$ had received specialized care for less than 30 days and 110 (25.5\%) for less than 1 week. Of the 970 patients who were still alive at the end of 2012, $543(56.0 \%)$ had received specialized care for more than a year.

Programs with a free-standing pediatric hospice provided care to 517 patients $(36.9 \%)$. There were statistically significant differences between children who received care through a program with an integrated hospice versus those who received care through one of the other programs (Table 2). Significantly fewer children in the hospice-affiliated programs were younger than 1 year of age at the time of referral (160 [30.9\%] v. 348 [39.4\%], $p<0.01$ ), and significantly more had a disease of the nervous system $(219[42.4 \%]$ v. 156 [17.6\%]), died in a hospice/palliative care bed (52 [41.9\%] v. 14 [4.6\%]) or received specialized pediatric palliative care for more than 1 year (293 [56.7\%] v. 314 [35.5\%]) $(p<0.001)$.

Of the 105 children who died in a critical care setting, 48 $(45.7 \%)$ were younger than 6 months of age at the time of death, and $28(26.7 \%)$ were referred to pediatric palliative care a week or less before death. In addition, 23 (92.0\%) of the 25 children whose condition was due to an external cause (e.g., attempted homicide, accident, complications of medical or surgical care) and who therefore might have been expected to die in a critical care setting were still alive at the end of the study period.

Across Canada, 3247 children aged 19 years or younger died from all causes in 2012. A total of 930 children died as a result of external causes, leaving 2317 children for whom pediatric palliative care may have been appropriate based on diagnosis. Of the 2317,431 (18.6\%, 95\% confidence interval $17.1 \%-20.3 \%)$ received specialized pediatric palliative care. Recent and validated estimates of the prevalence of lifethreatening conditions among children in Canada suggest that

Table 1: Program staffing and number of children receiving care at programs offering specialized pediatric palliative care in Canada in 2012

\begin{tabular}{|c|c|c|c|}
\hline Program & $\begin{array}{l}\text { Year program } \\
\text { started }\end{array}$ & $\begin{array}{c}\text { No. of } \\
\text { patients }\end{array}$ & Staffing, FTE \\
\hline \multicolumn{4}{|l|}{ Programs including free-standing hospice* } \\
\hline $\begin{array}{l}\text { Canuck Place Children's Hospice/BC Children's Hospital, } \\
\text { Vancouver }\end{array}$ & 1995 & 250 & $1.5 \mathrm{MD}, 2.4 \mathrm{APN}, 2.4 \mathrm{SW}, 1.0 \mathrm{BC}$ \\
\hline $\begin{array}{l}\text { Children's Hospital of Eastern Ontario/Roger's House, } \\
\text { Ottawa }\end{array}$ & 1999/2006† & 170 & $2.0 \mathrm{MD}, 1.0 \mathrm{APN}, 1.0 \mathrm{RN}, 0.8 \mathrm{SW}$ \\
\hline Alberta Children's Hospital/Rotary Flames House, Calgary & $2001 / 2009 \dagger$ & 97 & 3.4 MD, 0.8 APN 0.8 SW, 0.8 BC \\
\hline \multicolumn{4}{|l|}{ Programs based at hospital } \\
\hline Hospital for Sick Children, Toronto & 1986 & 326 & 2.16 MD, 2.0 APN, 1.8 BC \\
\hline Centre hospitalier universitaire de Québec, Québec & 2004 & 110 & 1.2 MD, 0.4 RN, 0.2 Psy \\
\hline Winnipeg Regional Health Authority, Winnipeg & 2006 & 97 & $1.0 \mathrm{MD}, 1.0 \mathrm{APN}$ \\
\hline Centre hospitalier universitaire Sainte-Justine, Montréal & 1999 & 67 & 0.5 MD, 2.0 APN, 0.8 Psy \\
\hline IWK Health Centre, Halifax & 1995 & 60 & $1.5 \mathrm{MD}, 1.0 \mathrm{APN}, 0.5 \mathrm{RN}$ \\
\hline Montréal Children's Hospital, Montréal & 1992 & 57 & $0.9 \mathrm{MD}, 0.5 \mathrm{APN}$ \\
\hline Stollery Children's Hospital, Edmonton & 1999 & 54 & $1.05 \mathrm{MD}, 0.8 \mathrm{RN}, 0.8 \mathrm{BC}$ \\
\hline $\begin{array}{l}\text { Children's Hospital London Health Sciences Centre, } \\
\text { London, Ontario }\end{array}$ & 2008 & 52 & $1.0 \mathrm{APN}$ \\
\hline Royal University Hospital, Saskatoon & 2011 & 51 & $0.3 \mathrm{MD}$ \\
\hline $\begin{array}{l}\text { Centre hospitalier universitaire de Sherbrooke, } \\
\text { Sherbrooke, Quebec }\end{array}$ & 2004 & 10 & $0.1 \mathrm{MD}, 0.1 \mathrm{SW}, 0.1$ Psy \\
\hline Total & - & 1401 & 39.61 FTE \\
\hline \multicolumn{4}{|c|}{$\begin{array}{l}\text { Note: } \mathrm{APN}=\text { advanced practice nurse, } \mathrm{BC}=\text { bereavement coordinator, FTE = full-time equivalent, MD = physician, } \mathrm{Psy}=\text { psychologist, RN = registered nurse, } \mathrm{SW}=\text { soci } \\
\text { worker. } \\
\text { "Only "core staff" are listed. Additional staff (e.g., nurses, personal support workers) provide front-line care when children are admitted to the hospice. } \\
\text { †Hospital-based program started before the hospice; therefore, both dates are included. }\end{array}$} \\
\hline
\end{tabular}




\section{Table 2 (part 1 of 2): Patient demographic and clinical characteristics, processes of care and outcomes of care} at programs with hospices versus other programs

\begin{tabular}{|c|c|c|c|}
\hline \multirow[b]{2}{*}{ Variable } & \multicolumn{3}{|c|}{ No. (\%) of patients } \\
\hline & Hospices & Other programs & Total \\
\hline All patients & $n=517$ & $n=884$ & $n=1401$ \\
\hline \multicolumn{4}{|l|}{ Age at referral, $\mathrm{yr}^{*}$} \\
\hline$<1 \dagger$ & $160(30.9)$ & $348(39.4)$ & $508(36.2)$ \\
\hline $1-4$ & $129(25.0)$ & $155(17.5)$ & $284(20.3)$ \\
\hline $5-9$ & $101(19.5)$ & $146(16.5)$ & $247(17.6)$ \\
\hline $10-14$ & $78(15.1)$ & $143(16.2)$ & $221(15.8)$ \\
\hline 15-25‡ & $46(8.9)$ & $88(10.0)$ & $134(9.6)$ \\
\hline Unknown & $3(0.6)$ & $4(0.4)$ & $7(0.5)$ \\
\hline \multicolumn{4}{|l|}{ Primary diagnosis§ } \\
\hline $\begin{array}{l}\text { Congenital malformations, deformations and } \\
\text { chromosomal abnormalities }\end{array}$ & $124(24.0)$ & $278(31.4)$ & $402(28.7)$ \\
\hline Diseases of the nervous system & $219(42.4)$ & $156(17.6)$ & $375(26.8)$ \\
\hline Neoplasms & $66(12.8)$ & $155(17.5)$ & $221(15.8)$ \\
\hline Endocrine, nutritional and metabolic diseases & $42(8.1)$ & $106(12.0)$ & $148(10.6)$ \\
\hline Conditions originating in prenatal period & $25(4.8)$ & $77(8.7)$ & $102(7.3)$ \\
\hline Mental and behavioural disorders & $12(2.3)$ & $14(1.6)$ & $26(1.9)$ \\
\hline Certain infectious and parasitic diseases & $6(1.2)$ & $19(2.1)$ & $25(1.8)$ \\
\hline External causes of morbidity and mortality & $6(1.2)$ & $19(2.1)$ & $25(1.8)$ \\
\hline Other & $17(3.3)$ & $59(6.7)$ & $76(5.4)$ \\
\hline Unknown & $0(0)$ & $1(0.1)$ & $1(0.1)$ \\
\hline $\begin{array}{l}\text { Patients alive at end of study period (Dec. 31, } \\
\text { 2012) }\end{array}$ & $n=363$ & $n=574$ & $n=937$ \\
\hline \multicolumn{4}{|l|}{ Time from referral to end of study period, $d \S$} \\
\hline$\leq 30$ & $31(8.5)$ & $75(13.1)$ & $106(11.3)$ \\
\hline $31-90$ & $9(2.5)$ & $53(9.2)$ & $62(6.6)$ \\
\hline $91-180$ & $22(6.1)$ & $57(9.9)$ & $79(8.4)$ \\
\hline $181-365$ & $40(11.0)$ & $107(18.6)$ & $147(15.7)$ \\
\hline$>365$ & $261(71.9)$ & $282(49.1)$ & $543(58.0)$ \\
\hline Deceased patients & $n=124$ & $n=307$ & $n=431$ \\
\hline \multicolumn{4}{|l|}{ Location of death§ } \\
\hline Critical care/emergency department & $22(17.7)$ & $83(27.0)$ & $105(24.4)$ \\
\hline Home & $21(16.9)$ & $71(23.1)$ & $92(21.3)$ \\
\hline General hospital unit & $16(12.9)$ & $69(22.5)$ & $85(19.7)$ \\
\hline Hospice/palliative care bed & $52(41.9)$ & $14(4.6)$ & $66(15.3)$ \\
\hline Labour and delivery unit & $6(4.8)$ & $35(11.4)$ & $41(9.5)$ \\
\hline Community hospital & $5(4.0)$ & $21(6.8)$ & $26(6.0)$ \\
\hline Other/unknown & $2(1.6)$ & $14(4.6)$ & $16(3.7)$ \\
\hline \multicolumn{4}{|l|}{ Time from referral to death, $d \S$} \\
\hline$\leq 1$ & $7(5.6)$ & $42(13.7)$ & $49(11.4)$ \\
\hline $2-7$ & $12(9.7)$ & $49(16.0)$ & $61(14.2)$ \\
\hline $8-30$ & $28(22.6)$ & $83(27.0)$ & $111(25.8)$ \\
\hline $31-90$ & $22(17.7)$ & $46(15.0)$ & $68(15.8)$ \\
\hline $91-180$ & $13(10.5)$ & $29(9.4)$ & $42(9.7)$ \\
\hline $181-365$ & $9(7.2)$ & $23(7.5)$ & $32(7.4)$ \\
\hline$>365$ & $32(25.8)$ & $32(10.4)$ & $64(14.8)$ \\
\hline Unknown & $1(0.8)$ & $3(1.0)$ & $4(0.9)$ \\
\hline
\end{tabular}




\begin{tabular}{|c|c|c|c|}
\hline \multirow[b]{2}{*}{ Variable } & \multicolumn{3}{|c|}{ No. $(\%)$ of patients } \\
\hline & Hospices & Other programs & Total \\
\hline \multicolumn{4}{|c|}{ Time from DNR order to death, $d$} \\
\hline$\leq 1$ & $18(14.5)$ & $50(16.3)$ & $68(15.8)$ \\
\hline $2-7$ & $22(17.7)$ & $57(18.6)$ & 79 (18.3) \\
\hline $8-30$ & $26(21.0)$ & $69(22.5)$ & $95(22.0)$ \\
\hline $31-90$ & $6(4.8)$ & $27(8.8)$ & $33(7.6)$ \\
\hline $91-180$ & $5(4.0)$ & $14(4.6)$ & $19(4.4)$ \\
\hline $181-365$ & $3(2.4)$ & $6(2.0)$ & $9(2.1)$ \\
\hline$>365$ & $17(13.7)$ & $15(4.9)$ & $32(7.4)$ \\
\hline No DNR order & $27(21.8)$ & $21(6.8)$ & $48(11.1)$ \\
\hline DNR status unknown & $0(0)$ & $48(15.6)$ & $48(11.1)$ \\
\hline \multicolumn{4}{|c|}{$\begin{array}{l}\text { Note: DNR }=\text { do not resuscitate. } \\
{ }^{*} p \text { for comparison }<0.01 \text {. } \\
\text { tIncludes } 71 \text { antenatal consults, } 25 \text { in hospices and } 46 \text { in other programs. } \\
\text { fSix patients aged } 20-25 \text { years were included in the sample. They may have continued in pediatric care because of severe developmental } \\
\text { disabilities or because death was considered to be imminent and a transfer to new care providers was seen as not being in the patient's best } \\
\text { interests. } \\
\$ p \text { for comparison }<0.001 \text {. } \\
\text { ПE.g., attempted homicide, accident, complications of medical or surgical care. } \\
\star \star * \text { Patients transferred to adult care }(n=21) \text { or discharged from palliative care }(n=12) \text { were not included as their status on Dec. } 31,2012 \text { was } \\
\text { unknown. }\end{array}$} \\
\hline
\end{tabular}

9.8 out of every 10000 children might benefit from pediatric palliative care services. ${ }^{12}$ Based on a population of 7826123 children aged 19 years or younger, ${ }^{13}$ the proportion who received specialized pediatric palliative care was 18.3\% (95\% confidence interval $17.4 \%-19.2 \%)$.

\section{Interpretation}

The number of children who received specialized pediatric palliative care in Canada more than quadrupled between 2002 and 2012 (Appendix 2, available at www.cmajopen.ca/ content/4/4/E562/supp1/DC1). However, most children (an estimated $81 \%$ ) who might benefit are not receiving these services. As well, $51 \%$ of the children who died in 2012 received these services only for the last 30 days of their lives. Of the 16 children's hospitals in Canada, 13 (81\%) now have a specialized pediatric palliative care program, whereas only $50 \%$ of children's hospitals in the US have such programs. ${ }^{14}$ Although staffing has not kept pace with the increasing number of children receiving care, given the number of programs in Canada and the fact that $82 \%$ of surveyed pediatricians indicated they have access to pediatric palliative care ${ }^{15}$ the availability of programs does not appear to be the major barrier to receiving care in this country. Unfortunately, other barriers clearly remain that prevent full and timely use of specialized palliative services by the children who need them.

Compared to 2002, lower proportions of children in 2012 had diseases of the nervous system (39.1\% v. $26.8 \%)$ and malignant disorders $(22.1 \%$ v. $15.8 \%)$, and a higher proportion had congenital conditions or conditions that originate in the perinatal period $(22.1 \%$ v. $36.0 \%)$. There were also differences in the location of death between the 2 cohorts, with a lower proportion dying at home in 2012 (43.9\% v. 21.3\%) and a higher proportion dying in a critical care (pediatric or neonatal intensive care) or emergency department setting $(12.3 \% \mathrm{v}$. $24.4 \%)$. The increased proportion of deaths in critical care settings over time is in line with research indicating that most children die in hospitals, most often in critical care settings. ${ }^{16,17}$ The change may reflect better integration of pediatric palliative care programs in these settings along with a change in culture, where palliative care is appropriately offered alongside continued attempts at life-sustaining therapies. However, referrals need to be made early enough for the team to have an impact on care. Just over a quarter of children who died in a critical care unit in 2012 met the pediatric palliative care team in the week preceding death. Children who died in critical care units primarily had chronic illnesses or conditions present from birth, and thus the possibility of death was likely evident much earlier. Delayed referral for these children raises concerns about the adequacy and timeliness of discussions about goals of care and whether families receive all the benefits associated with provision of expert pediatric palliative care.

Despite the prevalence of late referral, $60 \%$ of the children who received care through a program with a free-standing hospice in 2012 did so for over a year. The availability of respite care may be a deciding factor in parents' choosing to access a hospice, ${ }^{18}$ which may explain the longer stays in these programs. The preponderance of older children and those with neurologic illnesses in hospice programs may also be linked to the availability of respite. Free-standing children's 
hospices may offer a cost savings when patient-days in a hospice are compared with those in an acute care hospital. ${ }^{19}$ However, construction and operating budgets are substantial and are often reliant on philanthropic funding, which raises questions about the sustainability of this model. ${ }^{20}$ In areas where a pediatric hospice was available, $41.9 \%$ of children died in the hospice. This suggests that hospices may be an important alternative for families not comfortable being at home or where home care services are lacking. ${ }^{21,22}$

A higher proportion of children younger than 1 year of age at the time of referral received care in 2012 than in 2002 (36.2\% v. $24.0 \%) .{ }^{7}$ This proportion and the inclusion of antenatal referrals better represent the demographic features of childhood death: most children who die are younger than 1 year of age. ${ }^{11}$ The notion of perinatal palliative care has emerged in the literature over the last decade. ${ }^{23}$ Between $40 \%$ and $85 \%$ of parents choose to continue the pregnancy when a severe fetal anomaly is diagnosed, ${ }^{24-27}$ and involvement of a pediatric palliative care program may be associated with less-aggressive interventions at birth. ${ }^{27}$ Factors influencing the ability of programs to provide care to this emerging population include the location of the pediatric hospital in relation to obstetrical services at the adult hospital as well as logistical challenges around registration of an adult patient (the mother) in a pediatric hospital, even for outpatient consultations. The needs of the antenatal population fit with the principles of pediatric palliative care and represent an area of growth.

\section{Limitations}

Study limitations include those inherent with collection of retrospective data via chart review, although some sites prospectively collected data following the 2002 study for their clinical records and did not require chart review as part of the current study. Estimates of children who might benefit from palliative care were quite crude; however, we used 2 different methods, 1 relying on cause of death recorded in the vital statistics and the other on population-based estimates of prevalence. The 2 methods resulted in similar proportions, which increases our confidence in the accuracy of the estimates.

\section{Conclusion}

A fourfold increase in the number of children receiving specialized pediatric palliative care over a 10 -year period is encouraging, but there is still work to be done in addressing barriers to ensure all children who might benefit from specialized pediatric palliative care have the opportunity to receive it. For children who do receive specialized pediatric palliative care, late referral raises questions about whether children and families are receiving the full benefits these services may offer.

\section{References}

1. Spicer S, MacDonald ME, Davies D, et al. Introducing a lexicon of terms for paediatric palliative care. Paediatr Child Health 2015;20:155-6.

2. Friedrichsdorf SJ, Postier A, Dreyfus J, et al. Improved quality of life at end of life related to home-based palliative care in children with cancer. 7 Palliat Med 2015;18:143-50.

3. Wolfe J, Hammel JF, Edwards KE, et al. Easing of suffering in children with cancer at the end of life: Is care changing? 7 Clin Oncol 2008;26:1717-23.
4. Zhukovsky DS, Herzog CE, Kaur G, et al. The impact of palliative care consultation on symptom assessment, communication needs, and palliative interventions in pediatric patients with cancer. F Palliat Med 2009;12:343-9.

5. Schmidt P, Otto M, Hechler T, et al. Did increased availability of pediatric palliative care lead to improved palliative care outcomes in children with cancer? 7 Palliat Med 2013;16:1034-9.

6. Vollenbroich R, Duroux A, Grasser M, et al. Effectiveness of a pediatric palliative home care team as experienced by parents and health care professionals. 7 Palliat Med 2012;15:294-300.

7. Widger K, Davies D, Drouin D, et al. Pediatric patients receiving palliative care in Canada: results of a multicentre review. Arch Pediatr Adolesc Med 2007; 161:597-602.

8. Widger K, Cadell S, Davies B, et al. Pediatric palliative care in Canada. In: Knapp C, Fowler-Kerry S, Madden V, editors. Pediatric palliative care: global perspectives. New York: Springer; 2012:301-21.

9. Quill TE, Abernethy AP. Generalist plus specialist palliative care - creating a more sustainable model. N Engl f Med 2013;368:1173-5.

10. Harris PA, Taylor R, Thielke R, et al. Research electronic data capture (REDCap) - a metadata-driven methodology and workflow process for providing translational research informatics support. 7 Biomed Inform 2009;42:377-81.

11. The Daily — deaths and causes of death, 2012. Ottawa: Statistics Canada; updated 2015 Dec. 20. Available: www.statcan.gc.ca/daily-quotidien/151210/ dq151210f-cansim-eng.htm (accessed 2016 Feb. 26).

12. Chavoshi N, Miller T, Siden H. Mortality trends for pediatric life-threatening conditions. Am 7 Hosp Palliat Care 2015;32:464-9.

13. Annual demographic estimates: Canada, provinces and territories. Ottawa: Statistics Canada; updated 2015 Nov. 27. Available: www.statcan.gc.ca/pub/ 91-215-x/2012000/t512-eng.pdf (accessed 2016 Feb. 26).

14. Feudtner C, Womer J, Augustin R, et al. Pediatric palliative care programs in children's hospitals: a cross-sectional national survey. Pediatrics 2013;132: 1063-70.

15. Cyr C, Maisonneuve MH. Pediatric palliative care in Canada: a national survey of paediatricians. Paediatr Child Health 2015;20:153-4.

16. Ramnarayan P, Craig F, Petros A, et al. Characteristics of deaths occurring in hospitalized children: changing trends. 7 Med Ethics 2007;33:255-60.

17. Feudtner C, Feinstein JA, Satchell M, et al. Shifting place of death among children with complex chronic conditions in the United States, 1989-2003. FAMA 2007;297:2725-32

18. Steele R, Derman S, Cadell S, et al. Families' transition to a Canadian paediatric hospice. Part two: results of a pilot study. Int 7 Palliat Nurs 2008;14:287-95.

19. Pascuet E, Cowin L, Vaillancourt R, et al. A comparative cost-minimization analysis of providing paediatric palliative respite care before and after the opening of services at a paediatric hospice. Healthc Manage Forum 2010;23:63-6.

20. Kassam A, Wolfe J. The ambiguity of free-standing pediatric hospices. 7 Palliat Med 2013;16:716-7.

21. Rapoport A. A place to die: the case for paediatric inpatient hospices. Paediatr Child Health 2008;13:369-70.

22. Siden H, Miller M, Straatman L, et al. A report on location of death in paediatric palliative care between home, hospice and hospital. Palliat Med 2008;22: 831-4.

23. Wool C, Côté-Arsenault D, Perry Black B, et al. Provision of services in perinatal palliative care: a multicenter survey in the United States. 7 Palliat Med 2016;19:279-85.

24. Breeze AC, Lees CC, Kumar A, et al. Palliative care for prenatally diagnosed lethal fetal abnormality. Arch Dis Child Fetal Neonatal Ed 2007;92:F56-8.

25. Calhoun BC, Napolitano P, Terry M, et al. Comprehensive care for the family of the fetus with a lethal condition. 7 Reprod Med 2003:48:343-8.

26. D'Almeida M, Hume RF, Lathrop A, et al. Perinatal hospice: family-centered care of the fetus with a lethal condition. 7 Am Physicians Surg 2006;11:52-5.

27. Lee E, Stenekes S, Harlos M. Parental decision making factors and outcomes regarding fetal and neonatal lethal anomalies. F Palliat Care 2014;30:219.

Affiliations: Lawrence S. Bloomberg Faculty of Nursing (Widger), University of Toronto; The Hospital for Sick Children (Widger, Rapoport), Toronto, Ont.; John Dossetor Health Ethics Centre (Davies), University of Alberta; Stollery Children's Hospital (Davies), Edmonton, Alta.; Departments of Paediatrics and of Family \& Community Medicine (Rapoport), University of Toronto, Toronto, Ont.; Children's Hospital of Eastern Ontario (Vadeboncoeur), Ottawa, Ont.; Montreal Children's Hospital, McGill University Health Centre (Liben), Montréal, Que.; Children's Hospital London Health Sciences Centre (Sarpal), London, Ont.; Winnipeg Regional Health Authority (Stenekes), Winnipeg, Man.; Centre hospitalier universitaire de Sherbrooke (Cyr), Sherbrooke, Que.; Centre hospitalier universitaire Sainte-Justine (Daoust), Montréal, Que.; IWK Health Centre (Grégoire), Halifax, NS; University of Calgary (Robertson); Rotary/Flames House (Robertson), Calgary, Alta.; University of Saskatchewan; Royal University Hospital (Hodgson-Viden), Saskatoon, Sask.; Centre hospitalier universitaire de Québec (Laflamme), Québec, Que.; Child \& Family Research Institute (Siden); Canuck Place Children's Hospice (Siden), Vancouver, BC. 
Contributors: Kimberley Widger, Dawn Davies, Adam Rapoport, Christina Vadeboncoeur, Stephen Liben, Lysanne Daoust, Marie-Claude Grégoire, Marli Robertson and Harold Siden contributed to the study conception and design. All of the authors were involved in data acquisition and interpretation. Kimberley Widger performed the data analysis. Kimberley Widger and Dawn Davies drafted the manuscript. Adam Rapoport, Christina Vadeboncoeur, Stephen Liben, Amrita Sarpal, Simone Stenekes, Claude Cyr, Lysanne Daoust, Marie-Claude Grégoire, Marli Robertson, Heather Hodgson-Viden, Julie Laflamme and Harold Siden revised the article for important intellectual content. All of the authors approved the final version to be published and agreed to act as guarantors of the work.
Funding: The study was funded through a Connaught New Researcher Award from the University of Toronto. Kimberley Widger is supported by a Career Development Award from the Canadian Child Health Clinician Scientist Program and the Canadian Institutes of Health Research Strategy for Patient-Oriented Research.

Acknowledgements: The authors thank Sarah Brennenstuhl for assistance with statistical analysis.

Supplemental information: For reviewer comments and the original submission of this manuscript, please see www.cmajopen.ca/content/4/4/ E562/suppl/DC1 